\title{
Rabindranath Tagore
}

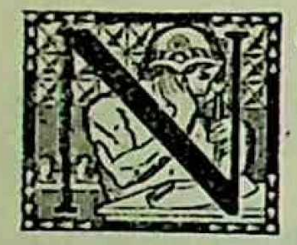

OS lo dió a conocer el premio Nobel. Mereciendo como pocos el premio de la Literatura, debió recibir con más títulos que nadie el premio de la Paz. Tagore es en nuestro siglo desorientado y convulso, la palabra de paz por excelencia. Apóstol del amor. armonizador como el Kabir de heterogéneos cultos en la unidad del puro ideal religioso. Rabindranath ha mirado en la trinidad del Amor, el Bien y la Belleza la única fuerza positiva. Asciende a la verdad por la escala radiante de la belleza. No es verdadero, no es bueno, no es noble, sino aquello que se vuelve música en sus oídos.

Arpa de Dios, siempre afinada por el amor, sólo se entrega a motivos (ideas o acciones) que al tocar su sensibilidad, resuenan como turbadoras melodias. Cuando el Gandhi llama a la India a la no-cooperación. Tagore confesta: -He tratado todos estos días, aguzando el oido, de descubrir cadencias en esta palabra; pero la idea de la no-cooperación, con su formidable volumen sonoro, su amenaza conglomerada, sus clamores de negación, nada me canta. .Si fuera un canto, dice, mi citara entonces pudiera aprisionar su melodia y me juntaría al coro. porque soy un cantor; pero como no es más que una disonancia. mi voz se ahoga y mi corazón está abrumado. Esta actitud de honradez suprema consigo mismo. podria interpretarse como pareja de la bella indolencia de Anacreonte cuando confiesa que su lira solamente suena amores y pide a los héroes que para siempre lo dejen en paz. Pero la poesía de Tagore es de tan excelsa calidad conceptual que desvanece, abrasándola en su llama. una tal sospecha.

El pensamiento de Tagore - que no hemos leído sistematizado en ninguna de sus obras - se desprende lácilmente de todas ellas.

La unanimidad de las religiones modernas concuerdan en la esencia, en el Ideal. Aspiran a la fraternidad, a la delicadeza, al Amor. Sus cultos son simbolos distintos de la misma verdad intangible: lo que importa es el triunfo del espíritu, de la pureza, de la bondad. Dios, inmóvil perfección, obra sobre el Cosmos, afrayéndolo a si, imán último: como en una escala más reducida el buen ejemplo puede más en la conducta de un niño que todas las fuerzas exteriores y coercitivas. 
El mal y el bien se disputan el Universo: La Luz y la Sombra. El mal es separación. destrucción. El bien es simpatia, amor. unión. El hombre que ama no discute el amor. lo siente como una verdad intuida a la que se entrega en luminosa embriaguez, e identificado con Dios, acrecienta la fuerza espiritual del Mundo, el Bien-que es en último término amor, y que en virtud de su propia naturaleza, atrae al propio mal para vencerlo, amándolo.

Belleza, verdad, nobleza, todo es unidad espiritual. ¿Creo, ha dicho Tagore, que la naturaleza se expresa con más fuerza en una florecilla que en un cañón Maxim,. La perfección tiene en si misma la mayor virtud dinámica- y a través de quebrantos impulsados y dolorosos cataclismos, el mundo marcha hacia ella, cada vez más considerable el caudal de Amor que Budas y Cristos hacen desbordar sobre la tierra. Tarde o temprano lo bello se impondrá. Nuestra vida es menos que un segundo en la evolución del espíritu. Amemos. y como amar es obrar, es la realidad, es lo positivo. Tagore que volvia de predicar por Europa la colaboración de las dos culturas, oriental y occidental, en la realización del espiritu. se negó a adherir al movimiento de no-cooperación que provocaba el Gandhi para libertar a la India del yugo inglés.

Tagore. maestro de amor. taumaturgo de la paz, es la figura más bella de nuestro siglo: pasa por los pueblos más apartados del globo como una nueva voz reveladora. .Para el que sabe amarlo el mundo se quita de encima su careta de infinito: se hace pequeño como una canción, como un beso de lo eterno. . Calcutta, Londres. Estocolmo, Nueva York. Buenos Aires, Berlin, Tokio, han sentido la augusta serenidad de su palabra, bajar como una paloma evangélica en el crepúsculo de su civilización de vértígo, incapaz de las preñeces inefables de las madres de los Cristos.

\section{¿TAGORE, POETA DE LA INDIA?}

Cada civilización tiene algo que la diferencia, dice un critico. La India es grandiosa; el Egipto, misterioso y simbólico: la Arabia, salvaje y enérgica. Mas la India no es eso sólo: la India lo es todo; renovadora perennal del espíritu. madre de todas las religiones, cuna de todas las civilizaciones. levadura inagotable de todos los entusiasmos generosos. Al lado del fervor exuberante. del maravilloso excesivo en que se derrama la lantasía de sus enormes epopeyas, erige Kalidasa la dulzura frágil. la ternura lánguida de Sakuntala. ¿Cuál es la tradición literaria de la India? ¿La representa Tagore? ¿O su arte se ha desnaturalizado por influencia de la educación europea del poeta? No creemos esto último: la poesía de Tagore no tiene precursores europeos. Para explicarla nos es preciso aceptar con Emerson, que la sociedad humana culmina en tres espiritus representativos: el que piensa. el que obra. el que canta. y ensanchando el concepto de sociedad basta confundirlo con la especie humana, afirmar que Tagore es el Cristo que canta.

Tagore está por sobre las nacionalidades, por sobre las razas, por sobre las zonas: es universal como todo lo que es misticamente profundo. Su poesía 
conmueve a europeos y asiáticos, a amarillos y blancos, a tropicales y sub-tropicales. Llegó cuando el planeta entero se consumia en sed de misticismo a hablarnos de un Dios eque oye las palabras bellas.

No buscamos en la poesía de Tagore el color local, el sentimiento del paisaje. la modalidad psiquica que nos revelen el poeta de la India. porque esta expresión nada significa en un país que es un compendio de todas las razas. un microcomos: buscamos la proyección de su excelsitud mental en sus emociones: al escuchar el matinal alboroto de sus arroyos melodiosos, nos deleitamos en prefigurar la montaña serena y azul de dónde proceden. El filósolo, por un razonamiento lento, alcanza las supremas realidades. El poeta, el gran poeta, de un impetu apasionado. se coloca en el mismo plano que aquél. En plano en que viven los espíritus extraordinarios. eso es lo que más nos interesa. Tratándose. del poeta. no nos detenemos a inquirir con qué recursos expresa su talento. como hace su obra. Nos apasiona, nos subyuga: no lo analizamos, lo amamos. En el caso de Tagore, nos repugna llamarlo genio: reconociéndole friamente la más vasta capacidad intelectual, parece que lo empequeñeciéramos, que le quitáramos alma, que aquella palabra humillase al sentido sentimental que en él exalzamos. Lo llamariamos más bien el Maestro o mejor el Iluminado. El lluminado: el que logró por la fuerza de su inspiración permanente la luz esplendorosa que de otro modo alcanzaron Platón y Plotino.

\section{TAGORE, VOZ NUEVA EN LA INDIA}

- Es el primero de nuestros santos que nos ha hablado de la vida: por eso le hemos dado nuestro amor., dice un coterráneo suyo.

En .El Asceta. Tagore nos revela su actitud ante la vida. Una muchacha hermosa y delicada, una de esas frágiles y tiernas figuras de mujer, como sólo las hay en el teatro Indio, como esa Sakantala que maravilló a Goethe y a Paul de Saint-Victor. la dulce Vasanti a quien la sociedad repudia, haciéndola culpable de la impureza de su padre, pide protección a un . Sanyasi, que también la rechaza. temeroso de que las tentaciones trastornen la serenidad de su espiritu concentrado y le hagan perder el camino de la Verdad. Este -sanyasi, simboliza el asceta tradicional: la joven repudiada, los placeres de los sentidos. Vasanti, roto su corazón. se marcha para siempre; pero el asceta, comprende que una fuerza nueva. le entrega el mundo en luminosa vibración, y le dilata el alma de modo que siente cantar dentro de ella las fuentes. los árboles, las brisas. los pájaros. Entonces abandona su retiro y sus reflexiones para buscar a Vasanti. inútilmente. y exclama:

-De hoy más, buscaré lo infinito en lo limitado, porque sölo el amor puede conducir a la Verdad.

Divina sencillez de fin del poema. Una mujer que se va para siempre, que 
nadie encontrará nunca: pero que ha despertado un espiritu al amor: un peregrino que al buscarla. pisa más blandamente la yerba de los prados y mira con más terneza las criaturas del Universo, que le hablan de su amor. (Vasanti. la amada fugitiva e imposible ¿no es también la belleza?).

El Amor, he ahi todo para el poeta de semblante nazareno y ojos abismados. La razón sólo no lo conducirá a la verdad: el amor infinito le alumbrará la noche del misterio. El ascetismo es negativo, es renunciación. alejamiento de la vida. El ideal es fluir. fluir en la corriente musical del Universo. Fluir con pureza de corazón. sin mutilar la existencia, sin renunciar a los sentidos. Demás está decir que esta actitud no envuelve el abandono de nuestro cuerpo a todos los impulsos y apetitos. El mismo amor. sentido como conpenetración en el alma universal, alzará espontáneamente limitaciones a los placeres de los sentidos.

Oigamos a Tagore en .Gitonjali, su obra maestra:

¿La libertad no está para mi en la renunciación. Yo siento su abrazo en infinitos lazos deleitables.

Siempre estás. lú escanciándome. llenándome este vaso de barro, hasta arriba con el fresco brebaje de lu vino multicolor, de mil aromas.

Mi mano encenderá sus cien distintas lámparas en tu fuego, y las pondrá ante el altar de tu Templo.

Nó, nunca cerraré las puertas de mis sentidos. Los deleites de mi vista. de mi oido y mi tacto soportarán tu deleite.

Todas mis ilusiones, arderán en fiesta de alegría, y todos mis deseos madurarán en frulos de amor.

Un santo humano, un pagano puro hasta la santidad. Tagore nos habla de una nueva pureza bien distinta del ascetismo. de una pureza que consiste en sentir. en una transparente serenidad intima. la dignidad de todas las cosas naturales: que la llama del espíritu arda en la lámpara de nuestros sentidos: pero que no se encienda la lámpara si no para dar una luz pura.

\section{EL SENTIMIENTO DEL POETA}

Una infinita nostalgia, embarga el espiritu de Tagore. Nostalgia ¿de qué? Nostalgia significa etimológicamente edolor del regreso.. edolor de anhelar el regreso. Regreso chacia dónde? Platón lo sabia. Pensar es recordar, tener el alma conciencia de su origen divino. de otro mundo. de otra realidad más alta que la percibida sensorialmente. Plotino, en el éxtasis, regresa a la sustancia divina de donde emanó su ser. Dentro de su sistema. dice Faguett. -el mundo es un Dios en el destierro con la nostalgia de sí mismo.

Esta es la nostalgia, de Tagore. En tal regreso, el corazón va de sorpresa. en sorpresa. Detrás de cada follaje susurrante, de cada flor, de cada manantial. hay una voz vaga y misteriosa que nos trae un mensaje de Dios. Leed este poema del .Jardineros.

Inquieto estoy y sediento de cosas lejanas, y el alma se me abre en un anhelo de llegar al fin de las remotas vaguedades. $Y$ tu flauta me llama. pene- 
trante, joh más allá sin nombrel y yo me olvido de que estoy sin alas, preso en esta cárcel para siempre.

Ando ansioso y desvelado; como un extranjero soy. en tierra dura. Tu aliento me llega, susurrando, en una lengua que mi corazón entiende como suya. una esperanza imposible. $Y$ tu flauta me llama, penetrante, ioh secreto lejanol, y yo me olvido de que no sé la senda, de que el alado corcel no está conmigo.

Desganado voy. peregrinando por mi propio corazón. En la niebla soleada de las horas lánguidas, iqué inmensa visión de ti se alza en el azul del cielo! $\mathrm{Y}$ tu flauta me llama, penetrante ioh último fin!, y yo me olvido que esta casa en que vivo sólo tiene cerradas todas las puertas..

Pero el poeta, que vibra de mil maneras y sufre con su pequeñez y con el dolor de los hombres alcanza finalmente la alegría cese arenal de gozo, hermano sólo del mar del Paraiso. .Estad siempre alegres, recomendaba San Pablo. La perfección vence al dolor, y es alegría suprema, alegría buena, alegría santa.

Nostalgia de la divinidad y alegría de vivir son los sentimientos que dominan la lírica de Tagore, sentimientos algo opuestos. que en su impresión contrasta, arrancan inagotablemente una trémula y luminosa sinfonia.

\section{TAGORE, POETA EMERSONIANO}

-El hombre, según Emerson, no es más que la mitad de sí mismo: su otra mitad es la expresión. ¿Qué diremos del Poeta? El poeta vive para expresarse. para expresar la Naturaleza, el Universo, la divinidad. Está siempre inspirado. vibrante, afinado, tendida la oreja, con curiosidad de amor, a la voz imperceptible de las cosas. No es poeta aquel que de vez en cuando siente el aguijón lírico, el estro, que afiebra y arrebata. El Poeta, el Elegido es siempre poeta. De los occidentales Verhaeren, se acerca como pocos a este tipo ideal. Ningún cantor de la tierra lo ha realizado como Rabindranath Tagore. No lo podríamos imaginar, sino, en armonia inninterrumpida con la música de cuanto existe. Todas las estaciones. los mundos, las alegrías. los dolores, resuenan en su alma abierta, profunda y asi sube y se repile siempre nuevo, como las brisas perfumadas de la Primavera. las formentas del Invierno y los mágicos ocasos estivales. Siempre do obseden palabras vagas que quieren exprimirse en música. Dice a Dios: Sé que tú te complaces en mi canto, que sólo vengo a ti como cantor. Y con el fleco del ala inmensamente abierta de mi canto. toco tus pies. que nunca pude creer que alcanzarias.

$\therefore$ Hay en su alma tan viva urgencia de expresión musical, tal afluir constantes de ritmos vigorosos, de ecos dorados o azules de cielos y bosques rumoreantes, que con una fe vehemente en si mismo. se reconoce el cantor de Dios, como Cristo se sabia su hijo identificado con lo infinito y consciente de su misión ineludible.

¿¿Qué divina bebida quieres tú. Dios mio. de esta rebosante copa de mi vida?

Poeta mio. ¿́te encanta ver la creación con mis ojos; oír, silencioso, en el umbral de mis oidos, tu propia armonía eterna? 
Tu mundo teje palabras en mi pensamiento y tu alegria las hace más melodiosas.

Té me das, enamorado, y luego sientes toda tu propia dulzura en mi.,

Y luego, dominado por la pasión lírica, quemado en el fuego de su canto. ratigado de.su propia melodia, le pide a su señor una tregua:

- Si se ha acabado el dia, si el viento rendido languidece, cúbreme bien con el manto de la sombra, como has cubierto a la Tierra con el sueño. como has cerrado tiernamente las hojas del loto desfallecido en el crepúsculo.

\section{LA EVOLUCION ESPIRITUAL}

De la milenaria aristocracia India, de la casta suprema de los brahmanes que por la soledad en plena naturaleza, la sobriedad de costumbres. la meditación y la fe en los más altos destinos humanos, se ha ido depurando siglo a siglo y afinándose de generación en generación. Tagore debió sentir muy joven la vocación por la poesía, que la tendencia hereditaria y el ambiente de su familia de intelectuales, la identificaron con el sacerdocio y el magisterio.

Se retira durante dos años en la soledad más completa, a oír inmóvil sobre un bote entre el rumor de las aguas fluviales y los pastos silvestres, la voz de la Naturaleza: quiere que sus mil susurros misteriosos se prolonguen musicalmente en sus venas remansadas: quiere escuchar el suspiro del loto al entreabrirse, las confidencias de las auras al besar las hojas; quiere que su corazón palpite con el ritmo poderoso de la Tierra. Y calla en un silencio preñado de armonía. en un amoroso escuchar inelable. Su espiritu contemplativo no ha menester más.

Cuando surta la palabra, parecerá que viene henchida de las mil fragancias de los bosques. del vuelo luminoso de los pájaros. del júbilo matinal de las fontanas, del calor de la tierra madura por la primavera. Sin embargo, la esencia ideológica de esta poesía no se concentrará en un panteismo naturalista. porque Tagore ama demasiado, es demasiado poeta. demasiado imaginativo, demasiado humano para no sentir como algo tangible dentro de la danza policroma de sus ilusiones, la realidad de Dios, ese Dios suyo. cercano, visible, que oye las palabras bellas.

- ¿Qué bella es tu pulßera encendida de estrellas. incrustada mágicamente con joyas de mil colores; pero cuánto más bella es tu espada con su curva de relámpago, como el ala abierta del pájaro divino de Vioanu cuando se tiende tranquilo en la irritada luz roja del ocaso.

Se estremece como la última respuesta solitaria de la vida extática de dolor. al golpe decisivo de la Muerte. Brilla igual que la pura llama de la vida, cuando abrasa la impureza diaria en su destello furibundo.

Qué bella es tu pulsera encendida de estrellas! Pero tu espada. Señor del trueno, está forjada con belleza definitiva iy es terrible a los ojos y al pensamiento! 
Esta primera elapa de Tagore se continúa en la delicada pasión amorosa de su juventud que llena las páginas exquisitamente frescas de su libro. .El Jardinero. La amada parece que viniera a recibir de labios del poeta la adoración muda de las cosas. de tal modo hincha el canto aquel ritmo juvenil que plenificó su corazón entregado al amor contemplativo de la Naturaleza. Tan vaga. tan aérea, tan pura es esta poesia que no se creeria voz humana, sino un soplo del viento luminoso sobre las rosas entreabiertas.

La segunda etapa de Tagore. la llena el amor de los niños. Es como el esinite párvulos, de nuestro Evangelio. Tagore, alma de niño encuentra acentos de una ternura insuperable. para cantar al niño tierno y precoz de su .Luna Nueva, el moderno evangelio de las madres. la mayor maravilla que el sentimiento humano haya exigido al corazón de los niños, y que se continúa en el - Cartero del Rey, pequeño drama lírico, patético en su sencillez. sublime en su emoción paternal. Alli encontramos a un niño enfermizo, a Amal que anhela conocer la vida, recorrer los caminos del mundo que sólo puede mirar a través de los cristales de su ventana. Amal pide a Sudra, hija de una florista que le traiga flores. Está casi moribunda y espera. ingenuo, una carta del Rey. Cuando Sudra vuelve con las flores. Amal ha muerto. QQue suavemente lastimero este poema! En él alcanza Tagore la plenitud de su ternura y de su sencillez.

¿Hay en él un simbolo? En Rabindranath todo es simbolo sin esfuerzo, sin intención de crearlo: Todo lo minúsculo es una copia del Todo, como en el sistema de Platón. las cosas pensadas son copias de las ideas tipos. Si trae juguetes al niño. amplifica esta visión sintiéndose a su vez como otro niño a quien Dios colma con el regalo de las cosas bellas de la Naturaleza. Cuando besa la cara del hijo comprende porqué Dios acaricia la frente del padre con las brisas del verano. Y he aqui de nuevo la eficacia del amor, para comprenderlo todo: el amor como fuente de conocimiento. como criterio supremo de verdad.

La escuela de Shanti-niketan concreta prácticamente esta pasión por la infancia. Es la escuela de la pobreza. de la sencillez y la espontaneidad. A veces nos recuerda la de Tolstoy en Janaía Poliana. República escolar, oración silenciosa en los crepúsculos bajo los árboles, conversaciones espirituales, canto y sobre todo amor a la Naturaleza. Tormar en sintesis, este ambiente de recogimiento lejos de la ciudad. Las lecciones se dán al aire libre: un niño, advierte en medio de una clase de Ciencias, que un pájaro canta gozosamente sobre sus cabezas en una rama; y la lección se suspende hasta que concluye aquel canto.

En Shanti-niketan escribió Tagore el . Gintajali, su obra predilecta.

Los niños acrecentaron el mundo de su corazón. pero Tagore sintió que una voz interior nueva le llamaba a más amplias realizaciones espirituales. Sintió que su misión no había terminado, después de haber dado su alma a la Naturaleza y a los niños. acarició un ideal más vasto, más social, más humanitario: acercar el corazón de los pueblos, unificar los anhelos humanos, en una sola aspiración de amor al prójimo. trabajar porque las dos culturas-oriental y occidental-colaboren en armonía por la perfección del hombre, por el triunfo del espíritu sobre la fuerza bruta, sobre la conquista material, sobre las vanas riquezas. Y hélo aqui 
peregrino por todas las rutas de la Tierra, apaciguando corazones con su aspecto venerable de santo y su palabra trémula de ternura.

\section{TAGORE. MAESTRO DE IDEALISMO}

-Yo estoy con los que muerden el polvo de todas las derrotas, ha dicho Tagore en la Cosecha de la Fruta. Hoy el propio Tagore es un derrotado en su patria. Después de su desacuerdo con el Gandhi, el agitador mistico que talvez sin quererlo llevó a su pueblo a proceder por medio de la violencia contra el extranjero, predicando el desprecio de todo lo europeo. Tagore explicó ante una enorme multitud sus ideas de concordia y amor. Romain Rolland cuenta que esta conferencia fué glacialmente recibida y algunos exaltados rompieron en silbidos de protesta.

¿Tagore derrotado?. Nó, el ideal nunca es vencido. El presente envuelve a veces entre nieblas el curso avasallador de los procesos espirituales. En ocasiones en que nos invade el desaliento, nos engañamos creyendo como Lucrecio que todas las cosas están hechas por manera de batalla, que todo, al fin de cuentas se reduce a lucha encarnizada. que hay que agitar las garras, apercibidos a responder el zarpazo felón e inevitable.

Pero si, en último término, ésta es la realidad. los sacerdotes, los poetas, los educadores aparten de ella los ojos, para ponerlos, aunque doloridos, en el Ideal. como algunos santos resistian la luz punzante y terrible, a cambio de mirar en el sol la cara de Dios. 